\title{
Elastic protection coatings for ship tanks to increase environment protection level
}

\author{
Janusz Kozak \\ Gdansk University of Technology
}

\section{ABSTRACT}

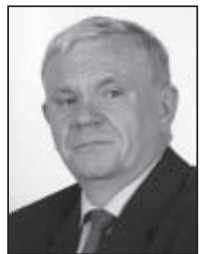

Greater and greater number of cargo ships sailing over small, restricted water areas can endanger the environment - in the case of disaster - by spilling fuel oil, carried in the ship's bottom tanks for its propulsion. In this paper is proposed an alternative solution (against that of double plating) in the form of the second, elastic protective barrier which would be able to decrease risk of spilling in the case of loss of ship's plating tightness due to collision or grounding.

Keywords : elastic protection coatings, ship tanks, environment protection

\section{INTRODUCTION}

During the last ten years a dramatic increase of number of cargo ships has been observed in the world fleet. The greater

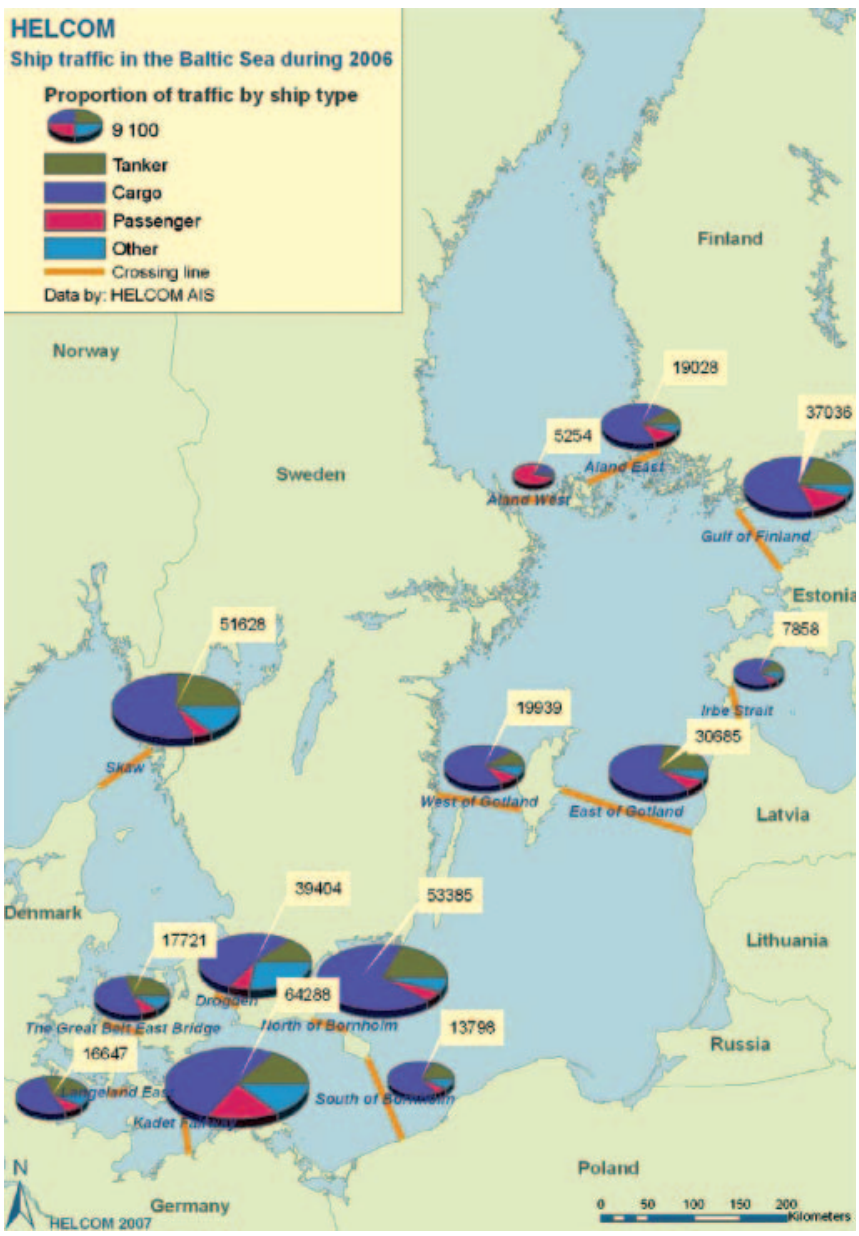

Fig. 1. Ship traffic in the Baltic Sea [2] ship traffic has been caused by progressing process of economy globalization. Many sea regions of the world have become more busy and hazardous for navigation, and one of them is the Baltic Sea [1]. On average about 2000 ships every day sail in this waters, Fig. 1.

These are ships of different types; out of the total number of 13600 ships crossing Skagen between July 2005 and October $2005-60 \%$ of them belonged to dry cargo ships, $25 \%$ - tankers, $7 \%$ - passenger ships and 8\% - other ships [2]. Main shipping routes in the Baltic are presented in Fig. 2.

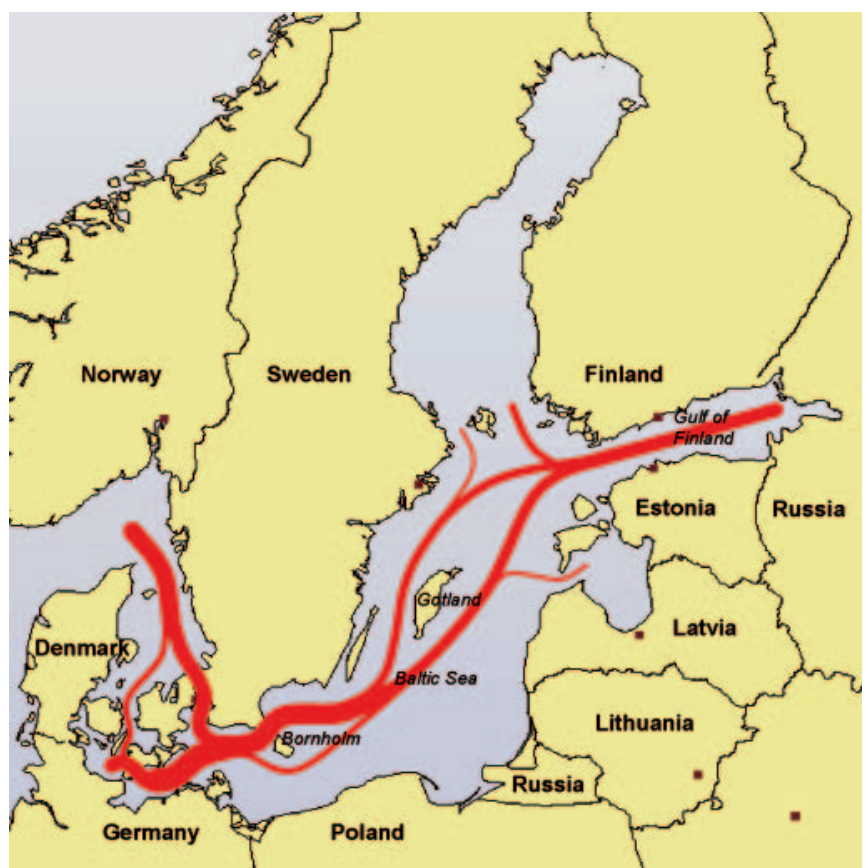

Fig. 2. Main shipping routes in the Baltic Sea [3]

Moreover, a further dynamic increase of number of cargo ships sailing in the Baltic waters is predicted - Fig.3 [2]. 


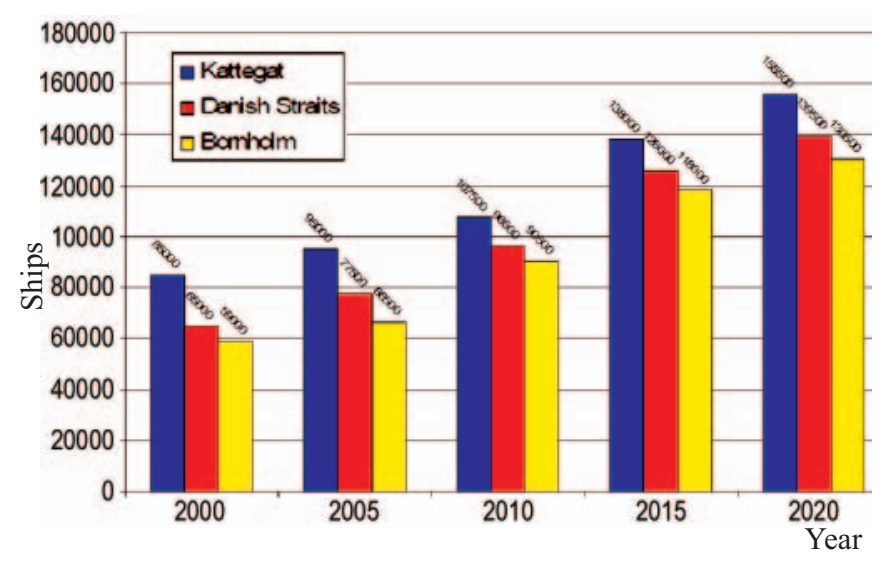

Fig. 3. Ship traffic intensity (ships/year) in the Baltic [4].

The Baltic Sea basin is a specific region of the world not only due to the busy shipping routes. It is a sea of a very limited amount of water exchanged with the ocean - the time necessary to completely echange its water with the Atlantic Ocean is estimated to be $25 \div 30$ years, which means that in the case of a greater oil spill in the region its consequences will be severe and long-lasting. According to the performed analyses [3] the probable profit loss resulting from tourism limitation in a spill suffering region would be many times greater than pollution removal cost. Additionally, in the Baltic waters - apart from shipping routes - in coastal zones are also carried out other activities such as fishing, tourism and operation of farms of wind power plants.

The very intensive ship traffic over the restricted area of the Baltic greatly influences occurrence number of sea accidents. The high traffic intensity, difficulty in navigation through the straits leading from the North Sea to the Baltic, often occurring bad weather conditions and other factors make that the Baltic is a sea region where many ship accidents occur year after year. The highest number of 146 sea accidents was recorded in 2005; as many as 13 of which resulted in pollution of the environment.

The map of particular kinds of the accidents together with indication of places of their occurrence is presented in Fig. 4.

In the years 2000-2006 the most frequent cause of ship accidents was grounding (46\%), the next one - ship-to-ship collisions (31\%). A failure of ship power plant or structure was responsible for disasters in 3\% cases, and fire - in 5\%. The most severe accidents which caused oil spills in the Baltic are listed in Tab. 1.

Tab. 1. The most severe pollutions caused by spills of oil product materials from ships in the Baltic waters [6].

\begin{tabular}{|c|c|c|c|}
\hline Year & Ship name & $\begin{array}{c}\text { Amount of } \\
\text { spilled oil }\end{array}$ & Place \\
\hline $\mathbf{2 0 0 3}$ & Fu Shan Hai & $1200 \mathrm{t}$ & $\begin{array}{c}\text { Bornholm } \\
\text { (Denmark/Sweden) }\end{array}$ \\
\hline $\mathbf{2 0 0 1}$ & Baltic Carrier & $2700 \mathrm{t}$ & $\begin{array}{c}\text { Kadetrenden } \\
\text { (Denmark) }\end{array}$ \\
\hline $\mathbf{1 9 9 8}$ & Nunki & $100 \mathrm{~m}^{3}$ & $\begin{array}{c}\text { Fjord Kalundborg } \\
\text { (Denmark) }\end{array}$ \\
\hline $\mathbf{1 9 9 5}$ & Hual Trooper & $180 \mathrm{t}$ & $\begin{array}{c}\text { Sund (Sweden) } \\
\text { Karlskrona } \\
\text { (Sweden) }\end{array}$ \\
\hline $\mathbf{1 9 9 0}$ & Volgoneft & $1000 \mathrm{t}$ & $\mathbf{2}$ \\
\hline
\end{tabular}

In the connection with the increasing risk of ecological disasters associated with sea transport, in the last years the European Union adopted two packages of legal instruments dealing with safety at sea, the so called principles : Erika I and

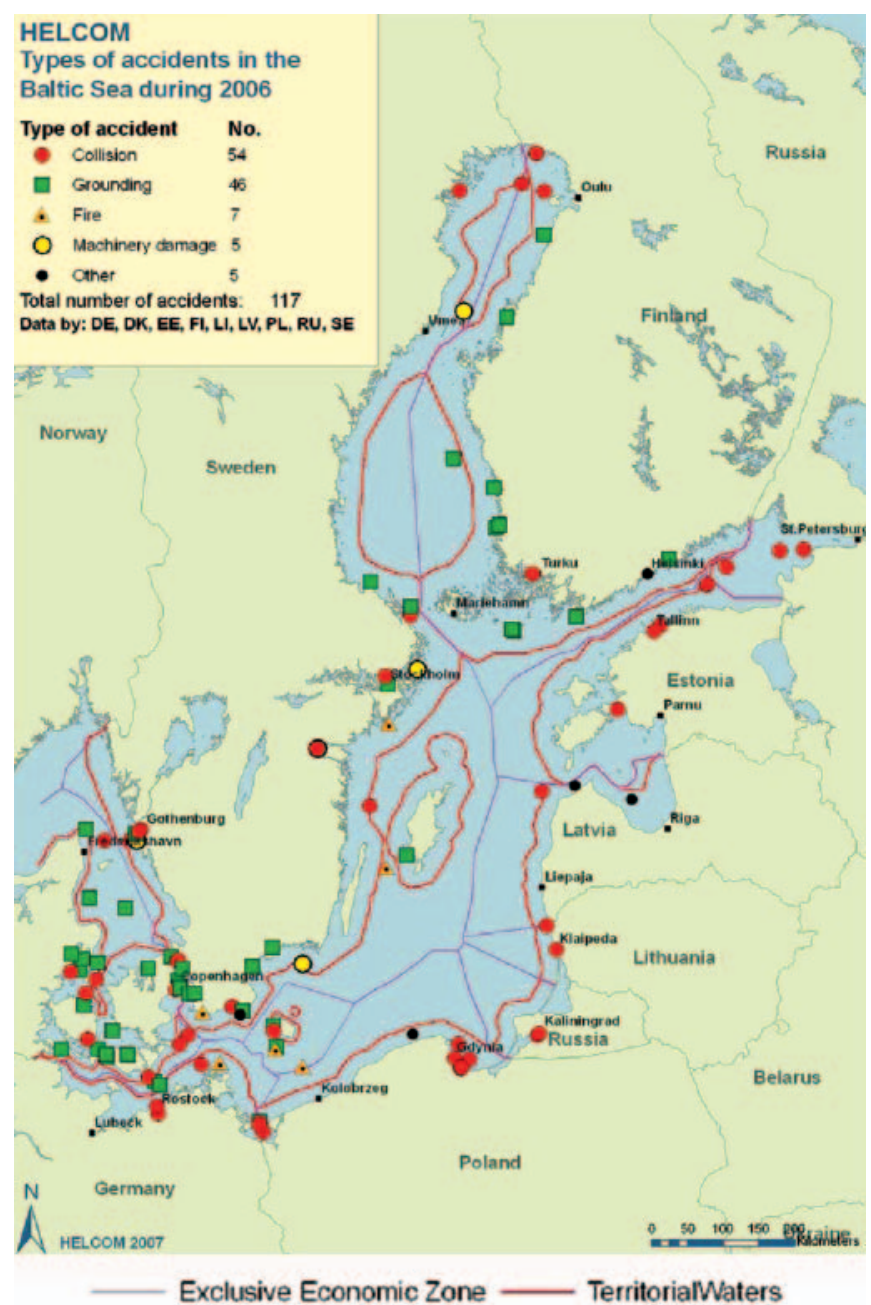

Fig. 4. Places where ship accidents occurred at the Baltic Sea in 2006 [5]

Erika II. As a result of their implementation the range of port control of ships was intensified and extended, and single side plating ships were banned from oil shipping; also, the European Maritime Safety Agency (EMSA) was established. In 2005 the European Commission prepared the package Erika III.

In the existing and being- in- force requirements for construction and equipment of new ships possible collisions and groundings have not been taken into account. Only basic design regulations concerning stability and floatability of damaged ships or amount of spill of liquid load from damaged hull are commonly accepted. However in 2004 Germanischer Lloyd (GL) introduced to its rules the notation COLL which determines degree of ship hull resistance (strength) against collisions [7]. The resistance is measured by comparing the strength against impact of strengthened ship side structure with that not strengthened of single plating. The only regulations directly concerning collisions are the requirements for ships intended for inland navigation on the Rhine (Switzerland, Germany, the Netherlands), introduced in 2003. The ADNR regulations require to so design structural elements of gas tankers as to make them able to absorb the energy of $22 \mathrm{MJ}$ released during collision against ship side structure [8].

Though for cargo tanks of oil cargo tankers the legal requirements have been recently made much more stringent, similar ones for fuel oil tanks are still lacking, nevertheless amount of fuel oil contained in them is often comparable with that of liquid cargo carried by a small tanker. The hazard becomes greater by the fact that most of such tanks is located in double bottom, i.e. in the zone very susceptible to failure both in the case of ship-to-ship collision and taking the ground or rock. 


\section{IDEA OF THE PROGRAMME CORET}

The above mentioned premises indicate that grounding or collision of e.g. a container carrier of medium size may lead to environmental pollution of the Baltic by the oil released from unseal single plating bottom tanks and its amount can be significant. In this connection was undertaken a research work aimed at elaboration of a way of lowering the risk of releasing oil spill in the case of collision, by introducing a second protection barrier. The idea of the project consists in adding an internal elastic oil-resisting coating placed inside the tank on a foundation which fills the tank in such a way as to ensure - in the case of tank plating tear occurring as a result of a collision - tightness of the tank by means of the elastic coating able to be displaced to some distance and thus preventing against oil spill in emergency, Fig. 5.

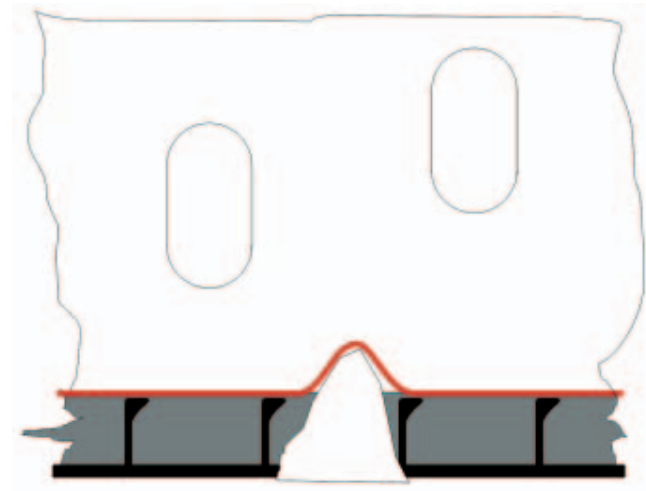

Fig. 5. Idea of the second elastic barrier for fuel oil bottom tank.

In order to elaborate such novel solution many problems should be first investigated, including the following:

$\Rightarrow$ elaboration of recipe for an oil resistant plastic material, inexpensive and suitable for coating it inside closed spaces in shipyard's conditions.

$\Rightarrow$ selection of a material for intermediate filling layer,

$\Rightarrow$ elaboration of an engineering process of applying the components of the barrier in industrial conditions with special taking into account difficult places such as corners, bends etc,

$\Rightarrow$ selection of the dimensions of the second barrier components: depth of the filling layer and thickness of the protection coating,

$\Rightarrow$ influence of the additional coating and filling material on corrosion rate of steel structure,

$\Rightarrow$ elaboration of a method for control of state of hidden surfaces,

$\Rightarrow$ making agreement with classification societies as to principles of implementation and use of the novel solution.

The mentioned problems constitute the subject of work carried out in the frame of the research project EUREKA E!3614 „CORET”: “Elastic protection coatings for ship tanks to increase environment protection level". Below are presented results of a preliminary work associated with developing some of the above mentioned problems.

\section{COLLISION MODELING TO ESTIMATE DISTANCE BETWEEN THE SECOND BARRIER AND SHIP PLATING}

In order to compare behaviour of the tank structure having internal protection barrier with that of the classical solution, was performed a numerical analysis of behaviour of such structures during collision with an external rigid object, e.g. a rock. On the basis of technical documentation of double bottom of a medium container carrier (Lo. a. $=120 \mathrm{~m}$ ) a computational spatial model with introduced minor simplifications (where bulb plates were replaced by equivalent flat bars), was prepared. The model covers a fragment of fuel oil double bottom tank located in the middle part of ship hold. The rock was modeled in the form of a cone of the radius $r=50 \mathrm{~mm}$. The collision process was modeled as a slow (quasi-static) motion of the cone $(\mathrm{v}=10 \mathrm{~mm} / \mathrm{s})$, perpendicular to tangent line of the bilge in the place of contact. The depth of penetration of the cone was assumed equal to $500 \mathrm{~mm}$. The calculations were performed with the use of the LS-DYNA (v 9.71) software.

The computational mesh was formed from 13500 shell elements. For the cone the rigid body model of the type " 20 " was applied, and for the double bottom structure - that of the type "24" (of piece-wise linear isotropic plasticity). The elements which exceeded limit elongation values were automatically removed from the model. During numerical calculations of the ship/rock collision, to take into account the coming into contact of various elements of the model is necessary. The standard approach used in such cases consists in application of an automatic algorithm for monitoring and determining which elements of the model are taking part in the contact. The generated model of the hull fragment together with the model of penetrating object is presented in Fig. 6. For the calculations the cone's movement velocity of $10[\mathrm{~mm} / \mathrm{s}]$ was assumed with a view of planned verification of numerical modeling results by those from testing real structural models.

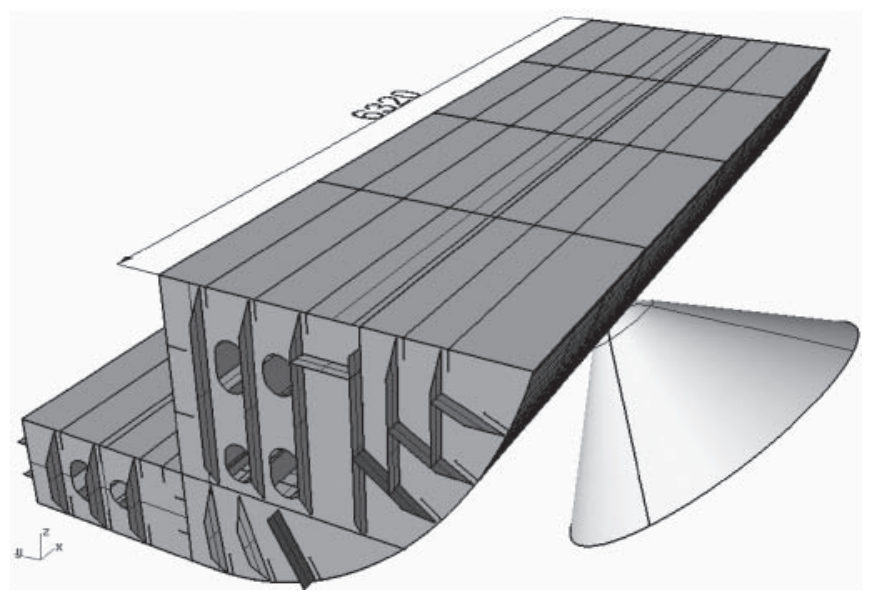

Fig. 6. Model for numerical simulation of collision

In Fig. 7 are presented the contours of von - Mises effective stresses in structural elements and outer plating for the selected time instant of simulation, $\mathrm{t}=62 \mathrm{~s}$.

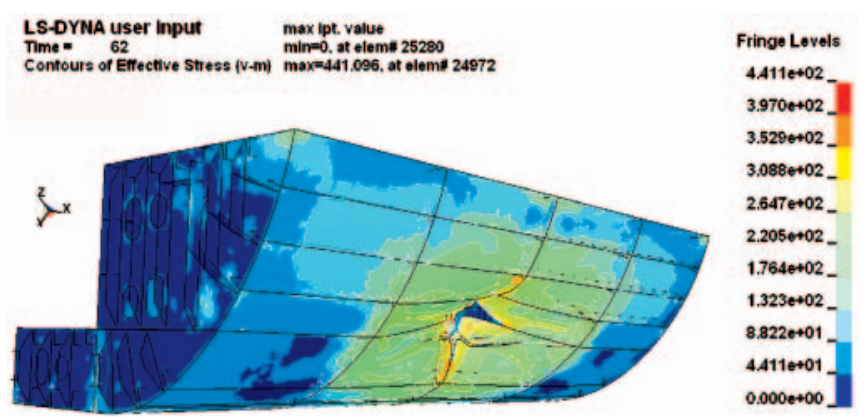

Rys. 7. The effective stresses in outer plating for the time instant $t=62 \mathrm{~s}$.

Fig. 8 shows the run of deformation energy changes in the structure during penetration. 
LS-DYNA, glstat, total energy

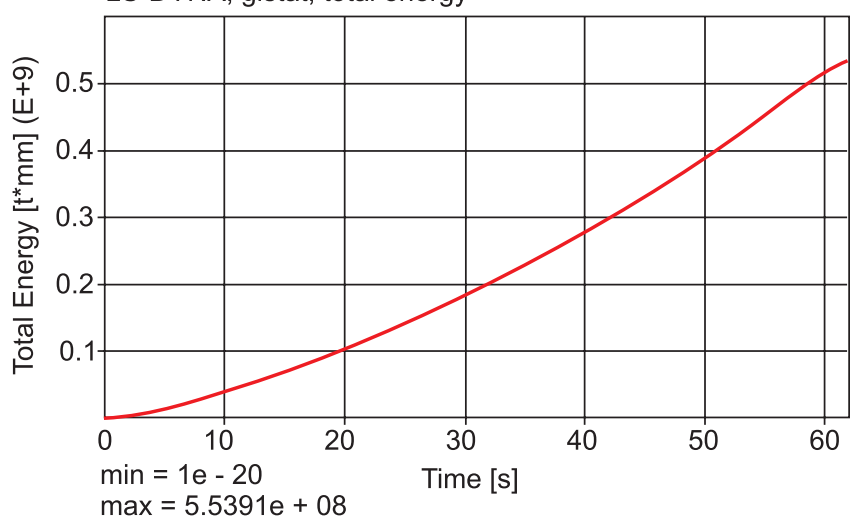

Fig. 8. Change of deformation energy of the structure during penetration.

The calculated deformation energy values extended by numerical calculations for the whole ship and verified with the use of the planned laboratory full-scale tests will finally serve for determination of behaviour of the internal elastic coating during the collision resulting in a tear damage of tank outer plating, and for evaluation of degree of effectiveness of the coating in preventing possible oil spill from the damaged tank.

\section{SELECTION OF A FILLING MATERIAL INTENDED FOR SUPPORTING THE SECOND BARRIER}

During searching for a filling material for supporting the elastic internal barrier, was performed a comprehensive research study to select the materials which satisfy majority of a dozen or so requirements, often contradictory to each other. Such filling material should be light in weight, non-flammable, non-gassing in an elevated temperature, non-toxic, noncorrosive, easy for implementing in industrial conditions, easily utilized and inexpensive, of course. After reviewing possibly applicable materials it was revealed that lightweight concretes can fulfill most of the postulated features. The concretes are of the volumetric density not greater than $2000 \mathrm{~kg} / \mathrm{m}^{3}$ in dry state. In land structures they are used to significantly lower weight of an element and/or its dimensions. The concretes are made by mixing cement mortar and various natural or artificial aggregates. Application of lightweight aggregates makes it possible to obtain the concretes of the strength exceeding 60 $\mathrm{MPa}$, at simultaneous reduction of structural weight by $25 \div 30 \%$ relative to the common concrete. It leads to a significant reduction of cost of shuttering, scaffolding and reinforcement, as well as to a reduction of dimensions of structural elements, thus - total volume of concrete and reaching a greater freedom of designing. The application of lightweight artificial aggregates to concretes results not only from the need of obtaining more lightweight structures but also from limited resources of rock aggregates and economic necessity of utilization of industrial wastes. This is especially important in the aspect of implementing the balanced development policy recommended by European Union.

A characteristic common feature of all lightweight aggregates is their porous structure and - as a rule - a lower strength than that of hardened cement mortar. Consequently, concretes made of the aggregates differ from common ones not only in their volumetric density but also other features as well as manufacturing process.

During the work on choice of parameters of concrete filling material the laboratory tests of mechanical properties of various combinations of concrete, aggregate and applied way of preparation of steel structure surface were carried out by using full-scale specimens. In Fig. 9 is presented the specimen tested to determine a degree of binding the filling material with the steel structure under tension, depending on a way of preparation of steel surface, and in Fig. 10 - the example record of deformation of the concrete filling material versus deformation of the steel structure.

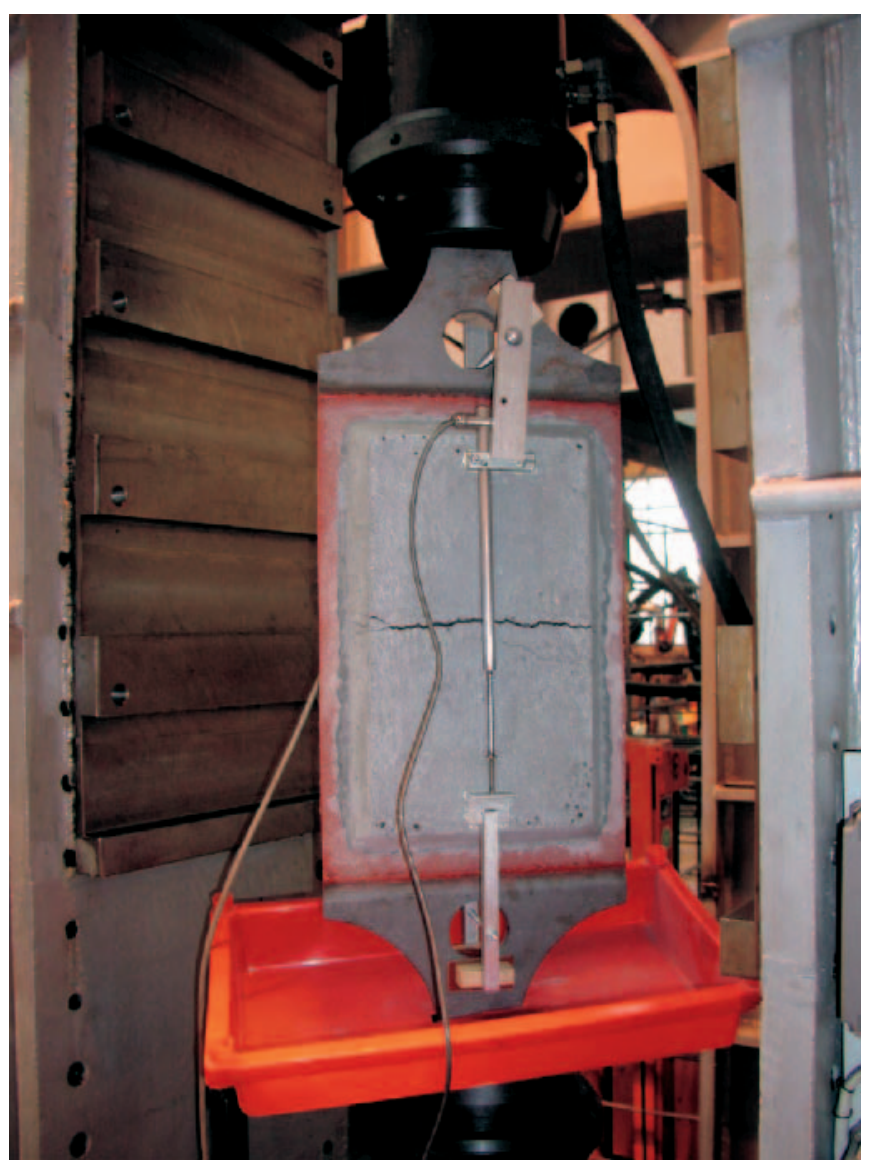

Fig. 9. Tests of mechanical properties of filling layer

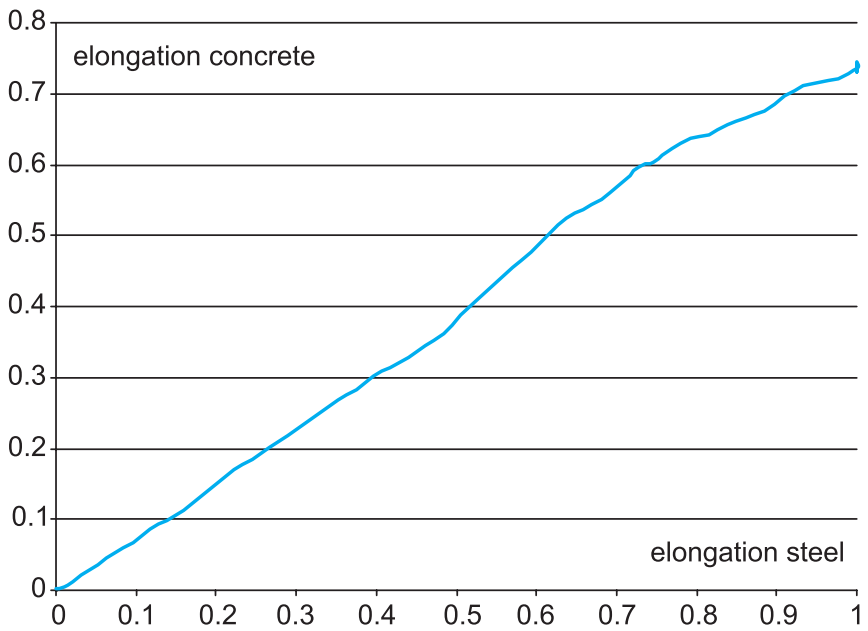

Fig. 10. Relative elongation of concrete filling material versus elongation of deforming steel structure.

\section{SUMMARY}

Large number of cargo ships sailing over small, restricted water areas such as the Baltic Sea can endanger - in the case of disaster - the environment by spilling fuel oil carried in the ship's bottom tanks for ship propulsion. 
An alternative solution (against the double plating structure) was proposed consisting in applying the second, elastic protection barrier to decrease risk of oil spill resulting from loss of tightness of ship plating as a consequence of e.g. collision or grounding.

Implementation of such solution would make it possible to increase safety of existing ships without necessity of their expensive rebuilding.

\section{BIBLIOGRAPHY}

1. Maritime Transport in the Baltic Sea. Draft HELCOM Thematic Assessment in 2006. HELCOM Stakeholder Conference on the Baltic Sea Action Plan 07.03.2006, Helsinki, Finland

2. Baltic Master: General Assumptions Of The Ship Safety On Southern And Western Baltic Sea, Report (M II part 2/4), Maritime University of Szczecin, 2006

3. SSPA Sweden AB : Socioekonomiska Effekter Av Större Oljepåslag - Scenariostudier För Halland, Skåne, Blekinge Och Kalmar Län, Rapport till Räddningsverket, September 2006
4. Report on ship's accidents in the Baltic Sea area for the year 2004. Issued by HELCOM 2004

5. Report on shipping accidents in the Baltic Sea area for the year 2006, HELSINKI COMMISSION, August 2007

6. Baltic Master : Statistics on accidents and sea traffic, August 2006

7. Germanischer Lloyd : Strengthening against Collisions, Rules for Classification and Construction, Ship Technology Part 1 - Seagoing Ships, Chapter 1 - Hull Structures, Section 33, Germanischer Lloyd, Hamburg 1992

8. Rules for the Transport of Dangerous Cargo on the Rhine (in German, French and Dutch), http://www.ccr-zkr.org, ADNR 2003

\section{CONTACT WITH THE AUTHOR}

Assoc. Prof. Janusz Kozak

Faculty of Ocean Engineering and Ship Technology,

Gdańsk University of Technology Narutowicza 11/12

80-952 Gdańsk, POLAND

e-mail : kozak@pg.gda.pl

\section{Miscellanea}

\section{Solemn session to celebrate 90th birthday of Professor Doerffer}

If Prof. Doerffer had not passed away on 9 August 2006 he would have celebrated his 90th birthday on 21 April 2008. Just on the day the solemn session devoted to Prof. Doerffer was held at the Faculty of Ocean Engineering and Ship Technology, Gdańsk University of Technology, to commemorate this anniversary of the Professor, a person of merit for development of Polish shipbuilding industry, respectfully called the Nestor of Polish shipbuilders.In the Session took part a numerous group of persons graduated from this Faculty, educated under supervision of the Professor, managers and chairmen of shipbuilding firms, representatives of present scientific and didactic staff of the Faculty together with Prof. Dzida, Dean of the Faculty, at that very moment elected for second term of this office. Mrs Maria Teresa Doerffer, the wife of the Professor, together with the Professor's daughter Christine, the son Carol and his wife, two granddaughters and grandson were also present.

The session, organized by the Professor Doerffer Foundation established in December 2006, was opened by Mr Dzida, the Faculty's Dean, then Prof. Katulski, the University's vice-Rector for R\&D matters passed greetings in the name of the University's authority. The subject-matter part of the Session contained four presentations (papers). Prof. Rosochowicz told the still continued directions of Prof. Doerffer's scientific research and didactic activity over, and reminded that Prof. Doerffer promoted two full professors, five associate professors, ten doctors of science, and that he himself was honoured with six dignity appellations of honoris causa doctor. Connections of Prof. Doerffer with shipbuilding industry, especially with shipyards located in Gdańsk, Gdynia and Szczecin were discussed by $\mathrm{Mr}$ Skrzypiński, long-standing manager of the Office of FORUM OKRECTOWE, the Association of Shipbuilding Industry Employers, which was initiated and arranged by Prof. Doerffer in 1993. And, the Professor's son Carol made the audience acquainted with family life of the Professor and illustrated his presentation with many photos projected onto the screen.

Next, Mr Spigarski, editor, performed promotion of the last, fourth volume of the Professor's memoirs titled „Life and Passions”, having its subtitle „Retirement”, that was also edited - similarly as the third volume - by Mr Spigarski, and published in a very careful graphical form by the Foundation for Promotion of Shipbuilding Industry and Maritime Economy, the Publishing House specialized in publishing the books on shipyard and maritime economy problems. Prof. Mazurkiewicz told about his friendship and cooperation with Prof. Doerffer, especially in the times when both of them took the top positions in the University's authority, of the rank of Rector and vice-Rector. A solemn moment of the Session was the unvailing of the Commemorating Plate devoted to Prof. Doerffer, placed close to the then his office room, which was solemnized by the Professor's wife and Prof. Dzida, the Dean of the Faculty. (spi)

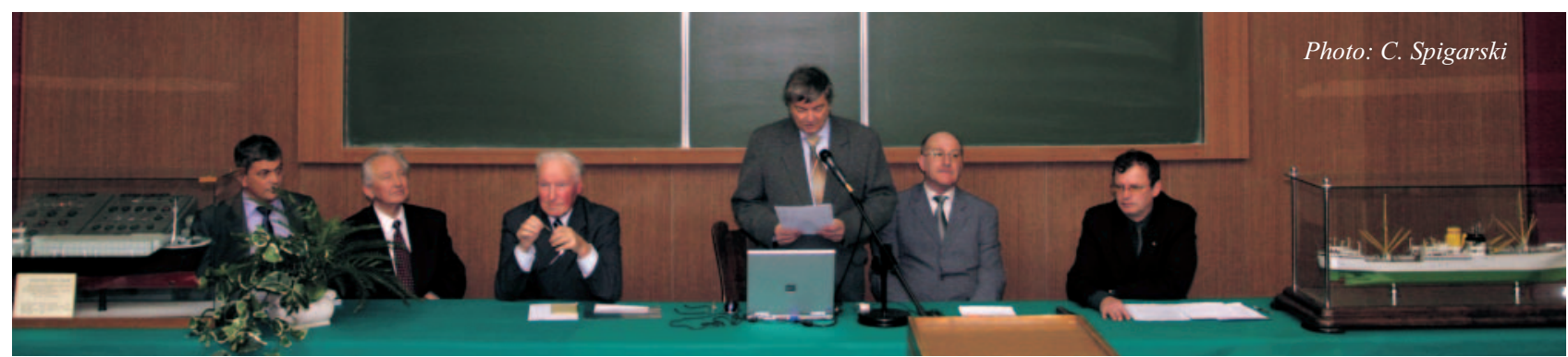

From the left side: Karol Doerffer, prof. Bolesław Mazurkiewicz, Stawomir Skrzypiński, prof. Krzysztof Rosochowicz, Jerzy Bunikowski, Marek Dzida 